\title{
Monitoring Bank Erosion in Hydroelectric Reservoirs With Mobile Laser Scanning
}

\author{
Marcus Vinícius Antunes de Moraes, Antonio Maria Garcia Tommaselli, Lucas Dias Santos, Mauricio Fava Rubio, \\ Guilherme Jardim Carvalho, and José Tadeu Garcia Tommaselli
}

\begin{abstract}
Bank erosion is caused by a set of factors requiring specific studies to understand them and their possible mitigation. Mobile laser scanning systems are applicable to the time-series analysis of survey data, mainly in areas with small changes over time, due to their high-spatial resolution and accuracy. Laser scanning systems equipped with global navigation satellite system/realtime kinematic (GNSS/RTK) positioning are advantageous because they demand fewer data postprocessing steps, and their accuracy is compatible with RTK accuracy. This study presents a set of techniques developed for marginal erosion monitoring using mobile laser scanning. Experiments to characterize the accuracy of surveys conducted with the mobile laser scanner MDL Dynascan M150 showed that the mean accuracy of surveys varies from 5 to $15 \mathrm{~cm}$ depending on the distance from the RTK base to the survey area. The results of an on-site case study are presented, which demonstrate the efficiency and accuracy of the proposed techniques and proves to be a very promising technique to support research on soil erosion.
\end{abstract}

Index Terms-Environmental monitoring, erosion process, mobile laser scanning.

\section{INTRODUCTION}

B ANK erosion is a natural process that occurs on the margins of water and is caused by waves, wind, and water infiltration. Human activities near or inside lakes and reservoirs can speed up the erosion processes, resulting in loss of productive areas, environmental damage(s), and lawsuits against the reservoir's managing company. Fig. 1 shows an example of a site subjected to the process of bank erosion.

Hydroelectric power generation is the base of the Brazilian energy matrix, and it accounts for more than $70 \%$ of the total energy used in Brazil. More than 100 hydroelectric plants are operating in Brazil, and all of them need access to large

Manuscript received March 7, 2016; revised April 26, 2016; accepted May 19 2016. Date of publication June 28, 2016; date of current version November 30, 2016. This work was supported by the Brazilian Agency of Energy (ANEEL), and in part by the Ministry of Education (CAPES/MEC).

M. V. A. de Moraes and L. D. Santos are with the Universidade Estadua Paulista, Presidente Prudente 19060-900, Brazil (e-mail: antunesdemoraes@gmail.com; dias_lucas_santos@hotmail.com).

A. M. G. Tommaselli is with the Department of Cartography, Universidade Estadual Paulista, Presidente Prudente 19060-900, Brazil (e-mail tomaseli@fct.unesp.br).

M. F. Rubio was with the Duke Energy-Geração Paranapanema, São Paulo 01046-925, Brazil. He is now with Amabelt Consulting, São Paulo 01002-010, Brazil (e-mail: mauricio.rubio@amabelt.com.br).

G. J. Carvalho is with the Duke Energy-Geração Paranapanema, São Paulo 01046-925, Brazil (e-mail: guilherme.carvalho@duke-energy.com).

J. T. G. Tommaselli is with the Department of Geography, Universidade Estadual Paulista, Presidente Prudente 19060-900, Brazil (e-mail: tadeu@fct.unesp.br).

Color versions of one or more of the figures in this paper are available online at http://ieeexplore.ieee.org.

Digital Object Identifier 10.1109/JSTARS.2016.2574704

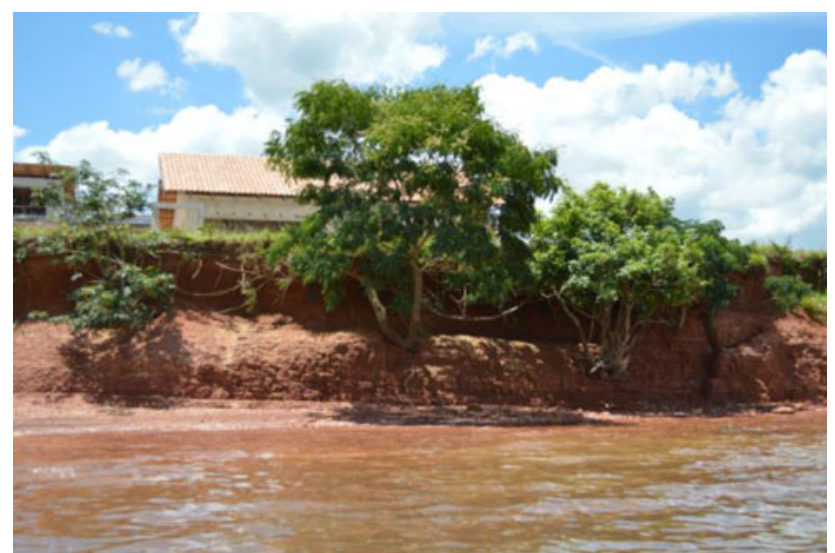

Fig. 1. Example of bank erosion at a hydroelectric reservoir on the Paranapanema River, Brazil.

reservoirs. During the initial flooding of a reservoir, the water makes contact with soils of areas that were originally dry and that are not suited to contact with water. These environmental and land-use changes can start erosive processes at the reservoir margins. Tropical climatic conditions, which include high rainfall rates, facilitate the occurrence of these erosion processes.

Considering the problems caused by bank erosion and the cost of environmental mitigation actions, Duke Energy - Geração Paranapanema and UNESP (São Paulo State University) developed a research and development $(\mathrm{R} \& \mathrm{D})$ project to monitor the marginal erosion process, to study and understand its causes.

To perform monitoring activities, a Measurement Devices, Ltd., (MDL) Dynascan M150 mobile laser scanner was used, installed on a boat. Field surveying and data postprocessing steps were performed by means of a methodology that were developed based on the environmental characteristics of Brazilian hydroelectric reservoirs. This paper presents the proposed methodology and achieved results of a validation experiment and a case study.

Laser scanning is a suitable technique to provide high resolution and accurate data for erosion monitoring. A mobile laser scanner, which is equipped with GNSS receivers and an inertial navigation system (INS), can be installed on a boat to provide an orthogonal view of the erosion process, which could not be achieved by conventional static terrestrial laser scanning. This technique is fast and accurate, and provides a large number of data points in a short time period.

The objective of this paper is to present a methodology for bank erosion monitoring using boat-based mobile laser scanning 
as well as data postprocessing and analysis that is suitable for hydroelectric reservoirs in Brazil.

\section{RELATED WORKS}

A mobile laser scanner installed on a boat has been used to perform monitoring of the erosion process in rivers and coastal cliffs. Nasermoaddeli and Pasche [1] developed a system composed of a terrestrial laser scanner that was integrated with a GNSS/RTK receiver and an echobatimeter. The system was installed on a boat to monitor erosion and deposition processes on the Hardebek-Brokenlander river meander in the city of Neumuenster, Germany. The main characteristics of this technique are its high-spatial resolution and precision, according to the authors. The sensor integration allows the creation of detailed profiles from the banks, despite the water level, at the time of the survey. Seven surveys were performed, which allowed the identification and quantification of several erosion/deposition processes with variable velocity during the period.

Poulton et al. [2] presented a methodology for monitoring cliff erosion, and the results of a case study performed in Happisburgh, Norfolk, England. The authors used a long-range terrestrial laser scanner (range longer than $2 \mathrm{~km}$ ) that was integrated to digital cameras for erosion monitoring. The survey's results gave dense and accurate point clouds for cliff modeling that were improved with semantic information from the digital images. Differential global positioning system was used for georeferencing of the point clouds. The authors highlighted the importance of taking into account the environmental factors of the region (winds, waves, anthropic activities, geology, etc.) and concluded that annual campaigns are enough to provide suitable data for erosion monitoring.

A methodology to monitor morphological changes caused by debris flow using differences between digital terrain model (DTM) from at least two epochs was presented in [3]. The data from terrestrial laser scanning were used to create the DTMs. A case study was performed in the Moscardo Torrent region in the Italian Alps. Three study areas across a watercourse were selected. One was near the source, the second was in an intermediate region of the watercourse, and the last was near the river mouth. Three surveying campaigns were performed in each study area immediately after debris flow events. The survey results enabled the calculation of the volume of eroded material, the volume deposited in lower areas, and the delineation of areas with significant changes. The authors highlighted the capacity of laser scanning to detect small magnitude changes due to its high resolution and accuracy as well as the necessity of quality control procedures to apply the technique based on differences between DTMs.

Dewez et al. [4] also used DTM differences to identify eroded areas on a cliff in Mesnil Val, France. In a study lasting two and a half years, six laser scanner campaigns provided data to identify 8500 eroded regions as well as to calculate their dimensions, areas, and volumes. The results were grouped by magnitude of processes. Statistics functions were used to estimate the recurrence period of each group of events.
TABLE I

MDL DyNASCAN TECHNICAL FEATURES

\begin{tabular}{|c|c|}
\hline \multicolumn{2}{|c|}{ General Information } \\
\hline Class 1 (FDA/ IEC) & (Class 2 with red dot pointer) \\
\hline Range & up to $500 \mathrm{~m}\left(1,640^{\prime}\right)$ \\
\hline Range resolution & $1 \mathrm{~cm}(0.4 ”)$ \\
\hline Scanner field of view & $360^{\circ}$ \\
\hline Scanner angle resolution & $0.01^{\circ}$ \\
\hline Scan rate & up to $30 \mathrm{~Hz}(1,800 \mathrm{rpm})$ \\
\hline \multicolumn{2}{|r|}{ Accuracy } \\
\hline Positioning & $\pm 5 \mathrm{~cm}\left(2.0^{\prime \prime}\right)$ \\
\hline Azimuth & $0.10^{\circ}$ \\
\hline Roll & $0.05^{\circ}$ \\
\hline Pitch & $0.05^{\circ}$ \\
\hline \multicolumn{2}{|c|}{ Dimensions } \\
\hline Weight & $11 \mathrm{~kg}$ \\
\hline Size & $\mathrm{L} 595 \mathrm{~mm} \times \mathrm{W} 240 \times \mathrm{H} 255 \mathrm{~mm}$ \\
\hline
\end{tabular}

A case study carried out in Carry-le-Rouet, France, for monitoring retraction of the coastline was presented in [5]. A set of laser scanning campaigns, which occurred every eight months, enabled the identification of regions where the coastline retracted by dimensions ranging from 0.5 to $2.0 \mathrm{~m}$. The authors concluded that frequent laser scanning campaigns are a suitable method of erosion monitoring in coastal areas.

In Brazil, some previous studies also have been performed for erosion monitoring. Amaro et al. [6] used a long-range terrestrial laser scanner to measure the volume of sediment deposited on the Ponta Negra beach, northwest region of Brazil. Two surveys conducted in September and November 2012 were used to generate DTMs of the area. The DTM analysis showed the occurrence of one sediment deposition event. The DTM generated by laser scanning was validated by comparison to a DTM produced from ground control points surveyed with the global positioning system (GPS). Adopting the same methodology, a study of deposits and coastline changes on Soledade beach were performed [7]. These authors stated that no study had been performed to develop a technique for erosion monitoring in hydroelectric reservoirs and assess its accuracy and operational effectiveness.

\section{MOBILE LASER SCANNING}

In this section, the laser scanner system features, details about boat refitting and survey procedures will be presented.

\section{A. MDL Dynascan M150 Mobile Laser Scanner}

The MDL Dynascan M150 Mobile Laser Scanner is a lightweight system equipped with one rotating pulse emission unit with capacity to emit 36000 points per second and rotate with a maximum frequency of $20 \mathrm{~Hz}$. A dual-antenna GNSS receiver with RTK provides the platform positioning and azimuth. A tactical grade INS MDL 5000 that has six-degrees of freedom computes the platform attitude at $100 \mathrm{~Hz}$. The INS gyros are capable of supplying measurements with $0.05^{\circ}$ of resolution in roll and pitch and $0.1^{\circ}$ in azimuth. The integrated GNSS/INS/RTK solution provides centimeter accuracy to kinematic positioning. Table I shows the MDL Dynascan technical features [8]. 


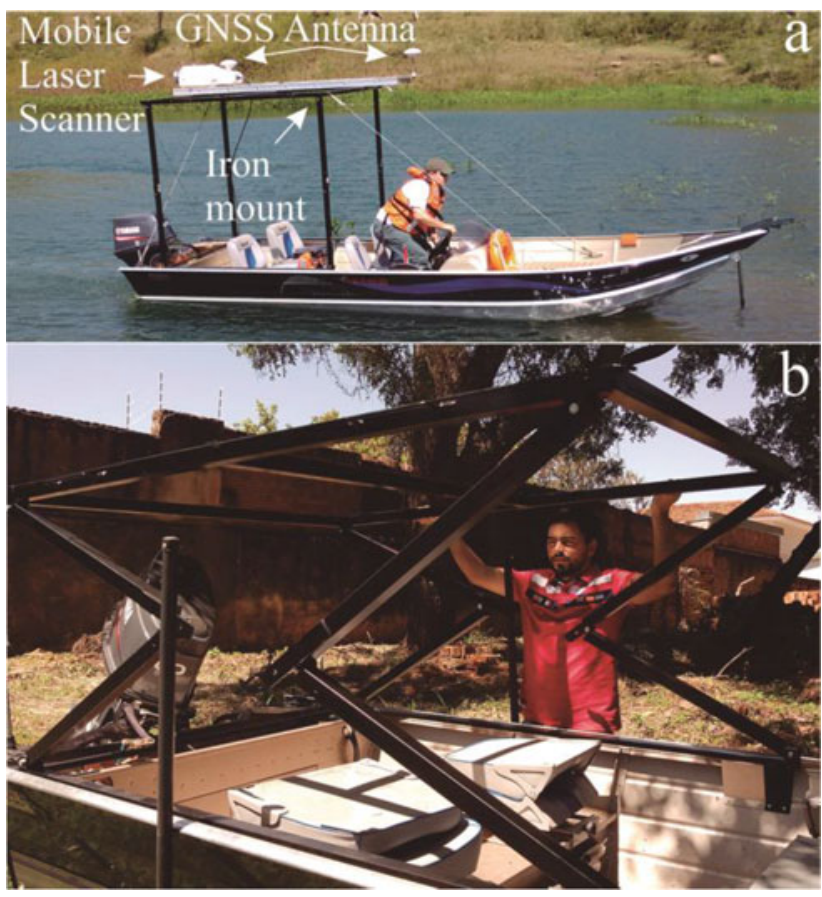

Fig. 2. (a) Motorboat equipped with laser scanning system and its components; (b) hinge system on the iron mount to facilitate the scanner and accessories installation.

A motorboat $5 \mathrm{~m}$ long was retrofitted with an iron mount that was specially designed to carry the Dynascan and its accessories. Fig. 2 shows the hinge device of the mount that was developed to facilitate the complete system installation. After the completion of the installation, the mount is raised to the survey position, which is $1.60 \mathrm{~m}$ above water level. Considering the mean height of the banks, 1.5 to $2 \mathrm{~m}$, this mount height allows surveying data for eroded areas and the natural terrain depending on the scanner-to-river-bank distance. Fig. 2 shows the metallic mount on the boat with the system components, which have known positions on the metallic mount. The base length between the two GNSS receivers was accurately measured by surveying techniques.

A Nikon D5000 RGB camera equipped with a singlefrequency GPS navigation receiver was jointly installed with the Dynascan at the iron mount to acquire images from the bank during the scanning sessions. These images were acquired by manual triggering and were used to support the filtering step described in Section IV.

\section{B. Data Surveying}

The surveying task consists of cruising along the reservoir on paths approximately parallel to the banks while keeping the velocity close to constant. The boat velocity is inversely proportional to the point cloud density; the greater the velocity, the lower the point density. In the experiments performed while sailing at a 10-m distance from the bank, keeping the velocity at approximately $3.5 \mathrm{~m} / \mathrm{s}$, and adopting a scan rate of $10 \mathrm{~Hz}$, it was possible to generate point clouds with a density of 500 points per square meter.
Precise positioning of the MDL Dynascan unit requires the installation of an RTK base at a point with previously known geodetic coordinates near the survey area. The RTK base receiver computes corrections and sends them to the rover receiver installed on the laser scanner via a ultrahigh-frequency radio link. The GNSS positioning, INS attitude, and RTK corrections are integrated on the Dynascan to provide real time and accurate navigation solutions for the platform.

After the RTK base installation, the rover equipment is activated and remains static for $5 \mathrm{~min}$ for GPS ambiguity resolution. The boat is then set in motion, and regular maneuvers are performed for the initial alignment of the INS. Aiming to reduce the INS alignment time, the route between the pier and the survey area follows a zigzag pattern. Near to the survey area, eightshaped maneuvers are performed for the INS fine alignment before starting the survey. All the INS, GNSS, RTK, and other sensor statuses are shown on the main screen of the Dynascan managing software.

QPS QINSy software manages the MDL Dynascan. Originally developed for a bathymetry survey, QPS QINSy is capable of managing several scatter and imaging systems. Its main screen shows the area surveyed, the accuracy status of the sensors, navigation information, and the estimated survey accuracy, all in real-time based on GNSS/RTK positioning accuracy and inertial navigation [9].

The RTK-aided positioning technique provides full access to the point cloud immediately after the end of the survey; thus, eliminating the need for GNSS/INS data postprocessing steps. During the survey, the QPS QINSy records the surveyed data in two databases: one with raw laser measurements, the other including the platform's position and attitude. Once the survey is finished, the databases are imported to QPS Qloud (an import/export software from the QPS suite). The final point cloud is exported to an ASCII file containing E, N, H, I (E, $\mathrm{N}$ are UTM projection coordinates; $\mathrm{H}$ is the geometric altitude related to WGS84, and I is the intensity of the returned beam) information from each measured point. This import and export step takes about two minutes for each surveyed kilometer of the banks.

\section{DATA PostrRocessing AND PRODUCTS GENERATION}

Data postprocessing comprises two main steps: a point cloud filtering to remove vegetation and anthropic features, and the generation of products. The products generated are: the points cloud, a DTM, height contours, crest line, and cross sections.

The data postprocessing methodology was developed to be applied by Duke Energy technical staff using the software suites integrated to the scanner hardware (Qloud and Qinsy, from QPS) and those usually adopted in their activities, for instance, GNSS data acquisition and processing and for geospatial database handling (ArcGis). For the cloud point filtering and editing, a commercial suite (Cyclone) was used.

During data surveying, all points over objects within the scanner operation range are recorded: bare soil, bank, vegetation, aquatic plants, and anthropic features, shown in Fig 3(a). Erosion analysis demands the knowledge of the terrain (bare soil) 


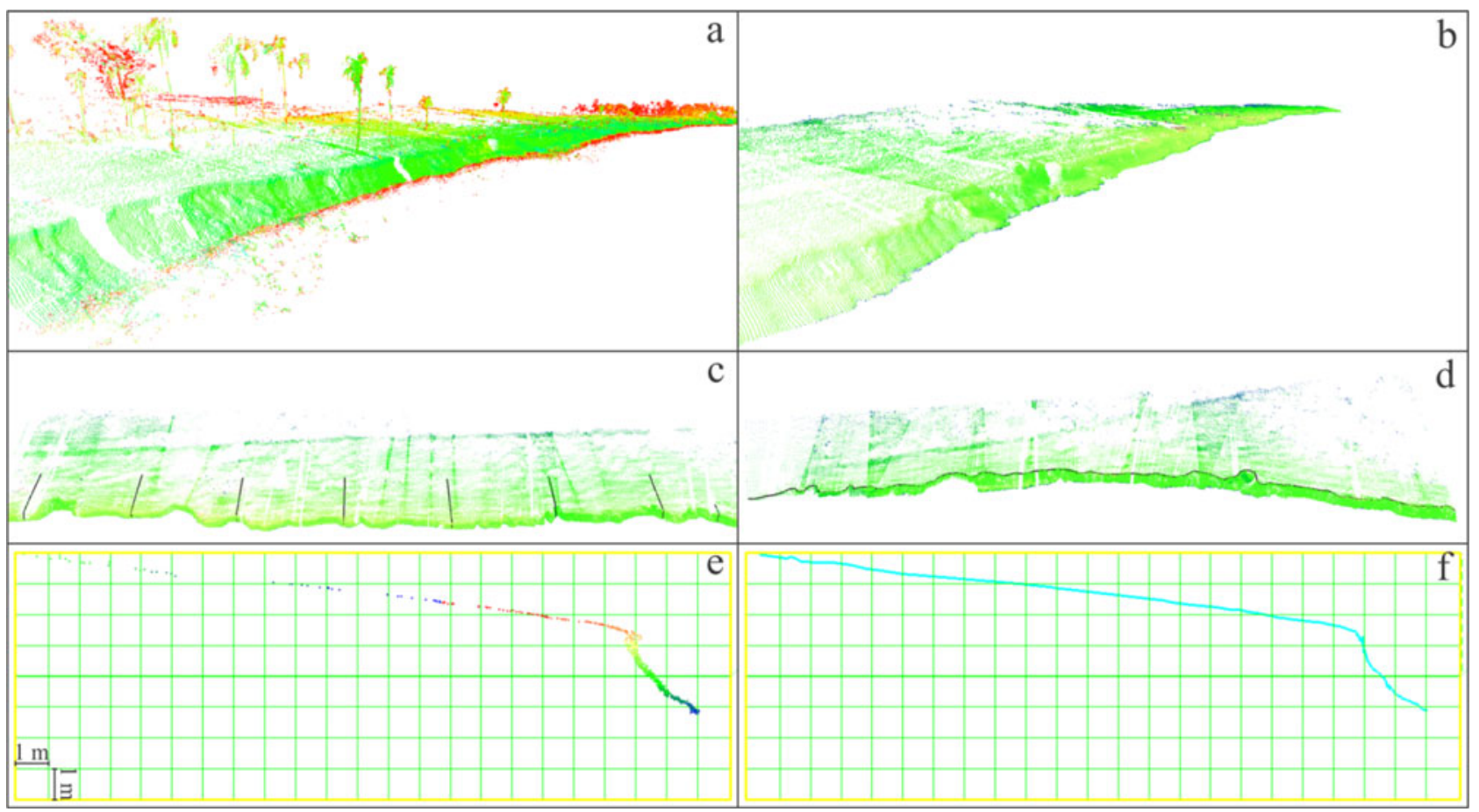

Fig. 3. (a) Raw point cloud containing all the recorded pulses; (b) filtered point cloud containing only bare soil; (c) filtered point cloud with the cross section positions highlighted; (d) filtered point cloud with crest line; (e) points extracted from the buffer during the cross-sectional creation; and (f) cross section line.

and bank. All other objects located in the area need to be purged from the point cloud for correct terrain and bank representation. Point cloud filtering is carried out manually using Leica HDS Cyclone 8.0 [10] software aided by visual analysis of the georeferenced RGB images from the bank. Because the accuracy of the georeferencing of the RGB images is approximately $4 \mathrm{~m}$, these images are used only to guide the operator in the editing step. In a future project, these images could be joined to the point cloud to enhance the automation of the editing step.

Water bodies located in tropical regions are usually surrounded by trees, shrubs, and grass. Trees near reservoir margins can be quickly removed from the point cloud manually or using automated algorithms. However, shrubs are located mainly in the bank, as shown in Fig 1, and filtering algorithms are not efficient enough to remove this class of object automatically. Some preliminary tests were performed with software such as CONUPO [11] and FUSION/LDV [12] aimed at gaining automated laser data classification. However, results of the classification with these software had low correctness rates, mainly because this scanner model does not record multiple pulse returns. In addition, there is a high computational demand when using these techniques.

The result of the filtering process is a point cloud representing only the natural terrain surface (bare soil) and banks, as shown in Fig 3(b). From this filtered point cloud, it is feasible to generate four products used in erosion process monitoring: a DTM, height contours, the crest line, and cross sections. The crest line, as shown in Fig 3(d), is a polyline representing the boundary between the bank and the natural terrain; cross sections are profiles of the bank representing its shape, as presented in Fig 3(c), (e), and (f), which are useful for analyzing the erosion dynamics over time and estimate the volume of eroded material.

The DTM was generated from the filtered point cloud in Leica HDS Cyclone using a triangular irregular network structure with approximately 50 points per square meter. Contours were also generated using Leica HDS Cyclone with an equidistance of $1 \mathrm{~m}$. Due to DTM roughness, jagged contours are generated that are later smoothed using the generalization tools on Arcgis 10.2.2 [13].

The crest line was created interactively directly over the filtered point cloud in two steps. First, some crest points were selected with the "Pick Point" tool on Leica HDS Cyclone; then, line segments were created from the picked points using the "Feature-to-Line" tool on Arcgis. This interactive step, with visual interpretation, was introduced after several unsuccessful attempts to automate this task. RGB images were also used to guide the crest line vectorization process.

Points belonging to cross sections were extracted with Leica HDS Cyclone using the "Section" tool. First, a reference straight line that was parallel to the river was created. Then sections were created from a buffer region over the point cloud oriented normal to this reference line. The buffer region is $0.5 \mathrm{~m}$ wide, and its amplitude is defined to cover the point cloud in height and depth. The 3-D coordinates of the points belonging to each section are exported to an ASCII file and imported into a $\mathrm{C}++$ program developed to create a 2-D line representing the bank shape, as shown in Fig 3(f). 


\section{Estimation OF EROdED MATERIAL}

Bank erosion evolves beginning with the washout of the bank base and resulting in the collapse of blocks of rocks, soil and vegetation. Based on these characteristics, the first step of erosion evolution analysis is to identify the eroded area between two scanning campaigns using the crest lines. The files containing the representations of crest lines of each scanning epoch are loaded into GIS software, and the differences between these lines are computed. The "Feature-to-Polygon" tool of Arcgis 10.2.2 was used to generate polygons from the differences in the crest line.

After the generation of the polygons of the eroded regions, a filtering process is necessary to eliminate areas with no significant dimensions or polygons formed from topologic errors between crest lines. A threshold of $15 \mathrm{~cm}$ in the wider region of each polygon was adopted, and values under this threshold were eliminated. This threshold value was defined empirically based on error propagation from the scanner precision and eroded area significance.

To analyze the evolution of the erosion process, some metrics were used based on the dimensions of the eroded regions, the area, and the eroded volume on each studied process. Integrating the individual areas of polygons defining erosions, the total eroded area is calculated, and the eroded regions were delimited using polygons. The coordinates of the start and end points of the eroded areas along the bank then define the area where cross sections are to be generated for further analysis.

Cross sections are created at the same location and orientation in all the scanning epochs where it is feasible to compare sections, which allows for the estimation of the bank retraction and the eroded volume of solid material [14].

With the previous steps, the main data about an erosion process can be defined; the number of eroded regions, the area, volume and dimensions of each region, and the total area and eroded volume. Other important data about the erosion processes are the evolution rate, which can be derived from the successive campaigns. It is important for tenants of the land in the neighboring areas to know the area being washed out, and that the reservoir manager has access to the volume being carried to water body. This evolution rate can be estimated in square meters per month with

$$
\text { Rate. } \text { Area }=\text { Eroded.Area } / \text { months. }
$$

Analyzing these values, erosion processes can be classified in terms of magnitude, environmental, and economic impacts, which can subsidize mitigation actions.

\section{ACCURACY ASSESSMENT}

The accuracy of the final data can be influenced by several factors. These factors mainly include the RTK signal power, the quality of the transmitted corrections, and the quality of the inertial measurements. Experiments were performed to assess the expected accuracy for the surveyed data for erosion monitoring due to the logistics difficulties involved in installing reference features for each monitored area.

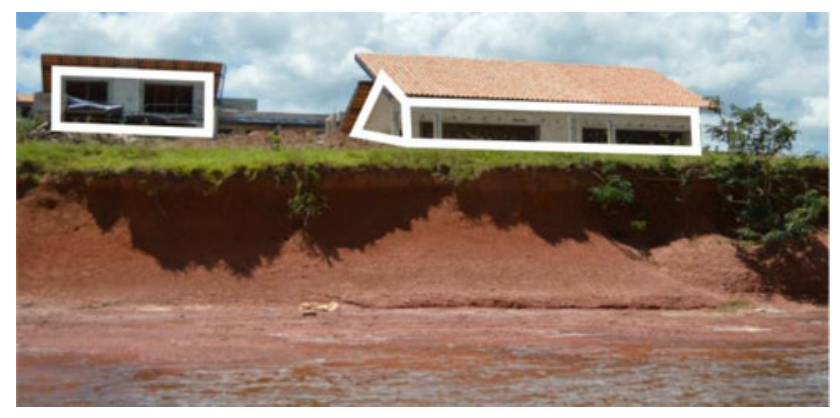

Fig. 4. Building façades facing the reservoir used as control features.

Three experiments were designed and conducted using two different test fields: one reservoir and one ground-based test field. The first test field was carried out in the neighborhood of the reservoir of the Chavantes Hydroelectric Plant, located on the border of the States of São Paulo and Paraná on the Paranapanema River, and (it) was composed of three building façades located on one of the banks of the reservoir and with one RTK base located at a distance of $3500 \mathrm{~m}$ from the survey area.

The second test field was carried out on the UNESP Campus in Presidente Prudente, São Paulo State, and was composed of building façades with three RTK bases at distances between 50 and $7600 \mathrm{~m}$ from the test field.

\section{A. Experiment 1-Boat-Based Laser Scanning Accuracy Assessment in the Chavantes Hydroelectric Plant Test Field}

The Chavantes Hydroelectric Plant is located in Chavantes County in São Paulo State and is managed by Duke EnergyGeração Paranapanema. The hydroelectric plant reservoir is formed by the Paranapanema River, which creates the border of São Paulo and Paraná States. The reservoir has an area of approximately $400 \mathrm{~km}^{2}$ with a perimeter of $1085 \mathrm{~km}$ [15]. Hundreds of eroded regions can be identified on the banks of the reservoir. The eroded areas have a mean length of 100 to $150 \mathrm{~m}$ and they cover $21 \%$ of the reservoir perimeter [17].

One of these erosion processes affects an urbanized area neighboring the reservoir. Fig. 4 shows some buildings with well-defined façades facing the reservoir. Due to the difficulties of installing targets at the margin of the reservoir, three façades were surveyed with topographic methods and used as control featuresto assess the mobile-laser scanning accuracy.

The façades were surveyed by single radial measurement (one angle and one distance) and the station coordinates were determined by GNSS positioning. Based on the surveyed points, the plane parameters defining the façades were estimated using the least squares method implemented in a MATLAB algorithm called "Fit-Plane." These planes were used as control surfaces to assess the quality of the laser scanning data.

This first experiment was performed using two datasets of boat based laser scanning in the Chavantes reservoir that were acquired in August and November of 2013. The datasets were originally acquired to perform erosion monitoring, and, thus, followed the standard procedures. The objective of the 
TABLE II

Average Distance BetweEn LASER SCANNING AND TOPOGRAPHIC DATASETS

\begin{tabular}{lccc}
\hline \hline Epoch & Target & $\begin{array}{c}\text { Average Distance to a } \\
\text { reference plane (m) and } \\
\text { and standard deviation }\end{array}$ & $\begin{array}{c}\text { Average } \\
\text { discrepancy per } \\
\text { epoch }(\mathrm{m})\end{array}$ \\
\hline August & Wall 1 & $0.186 \pm 0.037$ & $0.154 \pm 0.030$ \\
& Wall 2 & $0.191 \pm 0.042$ & \\
November & Wall 3 & $0.084 \pm 0.044$ & $0.140 \pm 0.041$ \\
& Wall 1 & $0.084 \pm 0.049$ & \\
& Wall 2 & $0.132 \pm 0.058$ & \\
& Wall 3 & $0.203 \pm 0.053$ & \\
\hline \hline
\end{tabular}

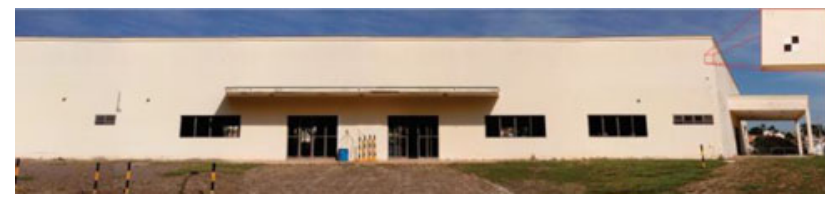

Fig. 5. Building façade in the UNESP test field, Highlighted is an example of the targets used for the topographic survey.

experiment was to assess the accuracy of boat-based laser scanning conducted using the proposed surveying methodology.

The distances of each point from the laser dataset to the reference plane, which were computed with ground surveying, were calculated to estimate the average distance between the point cloud and the reference values. Table II presents the results of the average distances calculated for each wall façade and each epoch.

By analyzing Table II, it can be observed that the average discrepancies between the reference planes and laser points are greater than the nominal system accuracy of $5 \mathrm{~cm}$. This loss of accuracy could be caused by the RTK signal quality, because the RTK base was located far from the survey area $(3500 \mathrm{~m})$, or because the reference data were acquired by nonredundant surveying (only one radial distance). Despite the loss of accuracy in comparison with nominal accuracy, the obtained values for discrepancies are acceptable for erosion monitoring considering the characteristics of Brazilian reservoirs.

\section{B. Experiment 2-Assessing the Influence of the RTK Base Distance in the Accuracy of Mobile-Laser Scanning in the UNESP Test Field}

The UNESP test field was set in a parking area with a building. The parking area was used for vehicle maneuvers and to install four artificial targets. The building façades, presented on Fig. 5, were also used, and some targets installed over these walls, as observed in Fig. 5. Three walls of this building were surveyed with topographic methods to be used as reference objects.

For this experiment, three RTK bases were located at different distances from the rover: base 1 at $50 \mathrm{~m}$, base 2 at $600 \mathrm{~m}$, and base 3 at 7,600 $\mathrm{m}$.

Due to the MDL Dynascan manner of real-time operation, it is unfeasible to separate the effects of GNSS positioning errors from IMU errors. The parameter that can be experimentally assessed is the distance from the RTK base to the rover. The

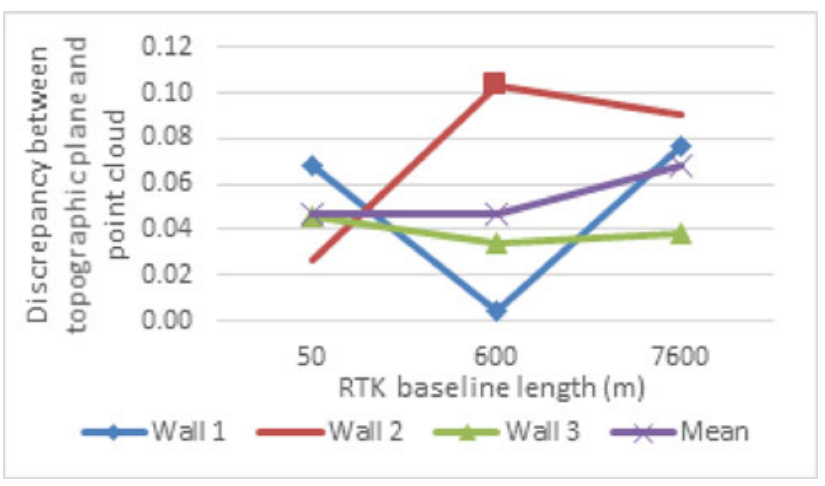

Fig. 6. Average discrepancies between the point cloud and the surveyed planes according to the RTK baseline length.

maximum distance achievable for an RTK system depends only on the heights of the base and rover antennas, the curvature of the Earth, and the atmospheric refractivity [16]. However, terrain variations, buildings, and trees reduce the RTK maximum distance and cause loss of signal, thus reducing the positional accuracy.

To evaluate the influence of the RTK baseline length on the accuracy of the mobile laser scanning, three building façades were surveyed by topographic techniques using redundant radial measurements and intersections from four different stations. Their coordinates were determined by GNSS positioning, and an accuracy of $5 \mathrm{~mm}$ was achieved for each surveyed point.

The three walls of the building façades were scanned three times using the three different RTK base stations. Before each survey, the recommended scanner initialization procedures were carried out to achieve the ideal scanning conditions. After scanning, the point clouds were filtered to keep only the façade walls for comparison with the reference data.

The data comparison procedure were similar to the first experiment. Based on the surveying data, the parameters of the three planes were estimated for each wall using the "Fit-Plane" algorithm. The distances between each point in the point cloud representing the wall and the fitted plane were calculated to estimate the mean discrepancy between the datasets and its standard deviations. Fig. 6 shows the average distances grouped by wall and RTK base in each case.

The average distances between the reference planes and laser scanning data in this experiment are closer to the nominal system accuracy of $5 \mathrm{~cm}$, except for wall 2 with the RTK at $600 \mathrm{~m}$, which gave average distances of $10 \mathrm{~cm}$. For baselines shorter than 1000 $\mathrm{m}$, the accuracy achieved is comparable to the nominal accuracy. However, by comparing the accuracies achieved with base 1 and base 3 , it is possible to see an increase on discrepancies of approximately $40 \%$, when there is an increase in the distance between the reference base and the laser scanner.

It can be concluded that the RTK baseline length influences laser scanning accuracy, but it was unfeasible to model this accuracy degradation analytically based on the acquired data. Further experiments using more base distances and controlled data would be required to establish a model for the prediction of accuracy for this equipment. 


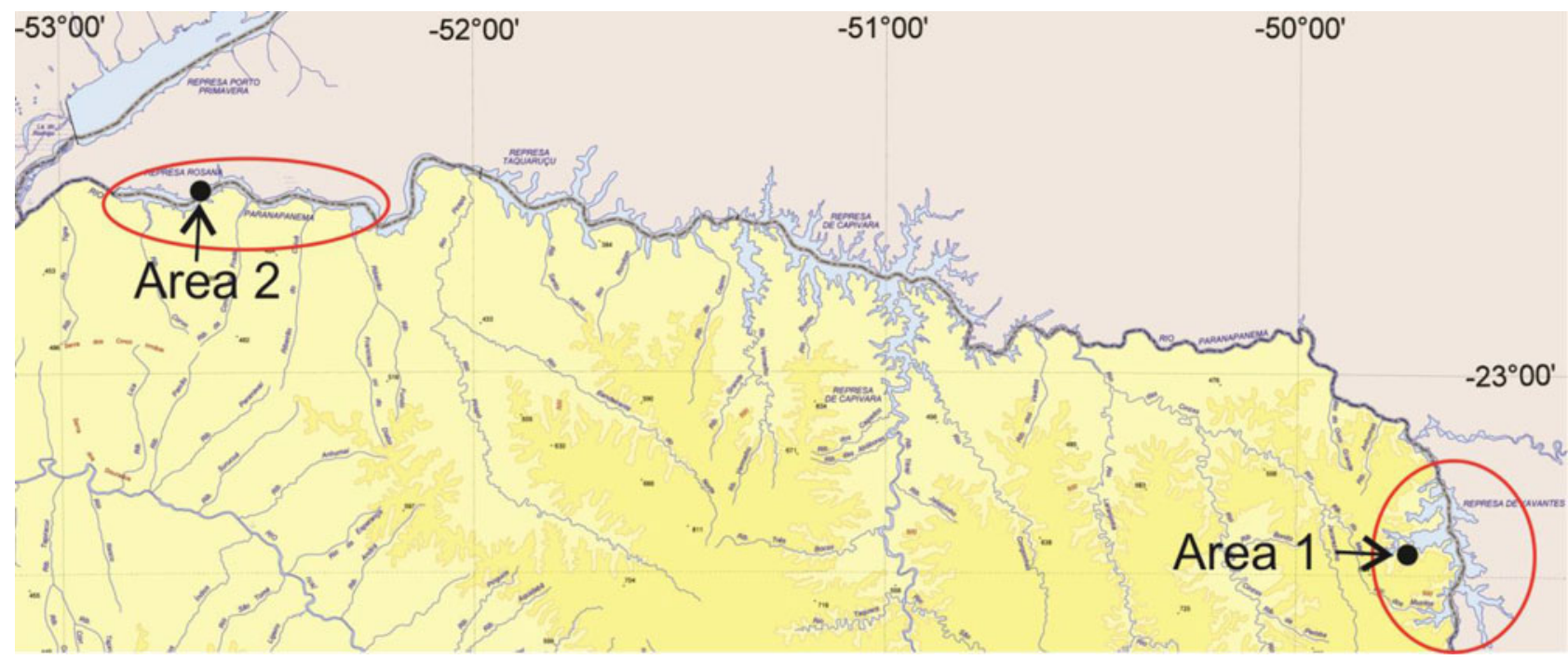

Fig. 7. Paranapanema River at the border of São Paulo and Paraná States, with the Chavantes (right) and Rosana (left) reservoirs highlighted.

\section{CASE Study-Monitoring BANK ERosion In A BRAZILIAN RESERVOIR}

The presented methodology for monitoring bank erosion was developed as part of an $R \& D$ project conducted in two hydroelectric reservoirs in Brazil.

During 28 months of monitoring activity, from July 2013 to November 2015, nine surveying campaigns were conducted in two hydroelectric reservoirs on the Paranapanema River, as shown in Fig. 7. Approximately 50 datasets of bank erosion processes were surveyed. Each dataset is composed of boat-based laser scanning data and several RGB images. This number of datasets is needed to correlate erosion rates with the reservoir characteristics, the hydroelectric plant operation, and the water regime.

In this study, only the results of monitoring two erosion processes are presented and analyzed to demonstrate the feasibility of the monitoring methodology. The reservoirs studied have distinct characteristics due to the mode of hydroelectric plant operation. The Chavantes reservoir is a flooding-type reservoir located at an altitude of $470 \mathrm{~m}$. There are mainly pastures, annual crops, and forests surrounding the reservoir and both margins of the reservoir are quite populated [15].

The Rosana reservoir is locate near the mouth of the Paranapanema River at an altitude of $255 \mathrm{~m}$. This reservoir is a run-ofriver type. The margin of São Paulo State is covered by pasture and forest, and the margin of Paraná State by annual crops and some remaining areas of pasture(s) and forest [15].

The first erosion process monitored (Area 1) is located at the Chavantes reservoir and is $630 \mathrm{~m}$ in length. Three surveys were performed in this area in November 2013 and June and November 2015 using the methodology proposed in Section III. Due to a long dry period, which drastically reduced the reservoir water level and prevented navigation, it was unfeasible to perform similar campaigns in the year 2014.

The laser scanning datasets were filtered, and the products demanded by erosion process analysis were generated as
TABLE III

Evolution Rate $\left(\mathrm{m}^{2} / \mathrm{MONTH}\right)$, AREa $\left(\mathrm{m}^{2}\right)$ AND Volume $\left(\mathrm{m}^{3}\right)$ EROded, AND LINEAR BANK RETRACTION (m) FOR AREA 1, CHAVANTES

\begin{tabular}{lcccc}
\hline \hline & November/2013 & June/2015 & November/2015 & Mean \\
\hline Evolution rate $\left(\mathrm{m}^{2} /\right.$ month $)$ & 0.49 & 0.06 & 14.84 & 5.13 \\
Eroded area $\left(\mathrm{m}^{2}\right)$ & 1.48 & 1.19 & 66.82 & 69.49 \\
Eroded volume $\left(\mathrm{m}^{3}\right)$ & - & - & 176.05 & 176.05 \\
& Bank retraction $(\mathrm{m})$ & & \\
Minimum & Maximum & Mean & Annual Mean \\
0.39 & 4.83 & 1.05 & 0.43 & \\
\hline \hline
\end{tabular}

described in Section V. Table III presents the analysis of the results.

The erosion process of Area 1 caused a loss of $69.49 \mathrm{~m}^{2}$ of productive area over two years in a bank length of $630 \mathrm{~m}$. In some locations, the bank had an average retraction of $5 \mathrm{~m}$. The volume of material eroded from the banks and deposited inside the reservoir was greater than $176 \mathrm{~m}^{3}$. The evolution rate demonstrated that the erosion grows at an annual average of $5.13 \mathrm{~m}^{2}$, which is a mean value for both the dry and wet periods. This is a typical example of the erosion evolution rate at the Chavantes reservoir.

Area 2 is a small area with a bank $75 \mathrm{~m}$ in length located at Rosana reservoir and was also scanned three times: in October 2014, February 2015, and October 2015. The same metrics used to characterize the Area 1 erosion process were applied to Area 2. Table IV presents the results of the monitoring activities.

As it was expected, Rosana reservoir is more prone to erosion due to its soil characteristics [15]. At a rate of $8.67 \mathrm{~m}^{2}$, this process caused the loss of $168.64 \mathrm{~m}^{2}$ of productive area in one year and a deposit of $305.73 \mathrm{~m}^{3}$ of material in the reservoir. The maximum bank retraction of 3.83-m contrasts with the area and volume eroded, which can be explained by the bank height of $2.5 \mathrm{~m}$. 
TABLE IV

Evolution Rate $\left(\mathrm{m}^{2} / \mathrm{Month}\right)$, AREA $\left(\mathrm{m}^{2}\right)$ AND Volume $\left(\mathrm{m}^{3}\right)$ ERoded, AND LiNEAR BANK RETRACTION (m) FOR AREA 2, ROSANA

\begin{tabular}{lcccc}
\hline \hline & October/2014 & February/2015 & October/2015 & Mean \\
\hline Evolution rate $\left(\mathrm{m}^{2} /\right.$ month $)$ & 9.85 & 2.47 & 13.69 & 8.67 \\
Eroded area $\left(\mathrm{m}^{2}\right)$ & 49.24 & 9.88 & 109.52 & 169.64 \\
Eroded volume $\left(\mathrm{m}^{3}\right)$ & 92.50 & 15.80 & 197.43 & 305.73 \\
\multicolumn{4}{c}{ Bank retraction $(\mathrm{m})$} \\
Minimum & Maximum & Mean & Annual Mean \\
0.19 & 3.83 & 1.48 & 1.05 \\
\hline \hline
\end{tabular}

\section{CONCLUSION AND RECOMMENDATIONS}

The aim of this paper is to present a methodology for bank erosion monitoring using boat-based mobile laser scanning aided by RTK positioning. This methodology was developed within the scope of an R\&D project adapted to the characteristic of Brazilian reservoirs and the available infrastructure. One objective of the R\&D project was to develop a methodology for systematically monitoring bank erosion and training of the Duke Energy-Geração Paranapanema technical staff to conduct these monitoring.

The surveying accuracy was estimated to be between 5 and 15 $\mathrm{cm}$ in the experiments performed for assessment of the accuracy of the data surveyed using the proposed methodology. Due to the erosion rates presented in Section VII and the surveying accuracies presented in Section VI, it is possible to conclude that the proposed methodology is suitable for bank erosion monitoring in hydroelectric reservoirs.

In comparison with other surveying techniques, the mobile laser scanner is advantageous due to its high-resolution data as well as the productivity and analysis allowed. Using surveying techniques limits data acquisition to the natural terrain landscape, and it is unfeasible to perform a detailed survey of the bank due to the cost or limitation of access to the area. Aerial and satellite Remote Sensing are suitable for crest line identification, but areas occluded by vegetation cannot be analyzed.

Careful planning of the field campaign with studies of the location of the RTK bases and line-of-sight visibility to the scanner receiver are recommended in addition to the selection of a suitable daytime period for GNSS and RTK surveying that consider ionospheric disturbances. Experiment 2 showed that lengthy RTK baselines or signal interruptions causes accuracy degradation in the point cloud.

\section{REFERENCES}

[1] M. Nasermoaddeli and E. Pasche. "Application of terrestrial 3D laser scanner in quantification of the bank erosion and deposition," Izmir, Turkey, 2008, pp 1-10.

[2] C. V. L. Poulton, L. R. Lee, P. R. N. Hobbs, L. Jones, and M. Hall, "Preliminary investigation into monitoring coastal erosion using terrestrial laser scanning: Case study at Happisburgh, Norfolk," Bull. Geol. Soc. Norfolk, vol. 1, no. 56, pp. 45-64, Jul. 2013.

[3] G. Blasone, M. Cavalli, L. Marchi, and F. Cazorzi, "Monitoring sediment source areas in a debris-flow catchment using terrestrial laser scanning," CATENA, vol. 123, pp. 23-36, Dec. 2013.

[4] T. Dewez, J. Rohmer, V. Regard, and C. Cnudde, "Probabilistic coastal cliff collapse hazard from repeated terrestrial laser surveys: Case study from Mesnil Val (Normandy, northern France)," J. Coastal Res., vol. 65, pp. 702-707, Jun. 2013.

[5] T. Mitchell, B. Chazaly, and G. Suarez, "Evaluation of coastal vulnerability with mobile laser scanning from a vessel," in Proc. Oceans Conf., San Diego, CA, USA, 2013, pp. 1629-1634.

[6] V. E. Amaro, A. L. S. Santos, A. C. Scudelari, and B. C. P. Costa, "Use of terrestrial-LiDAR for quantifying morphological changes in Ponta Negra Beach, Natal City, Northeast Brazil," in Proc. CoastGIS Conf., Victoria, BC, Canada, 2013, pp. 5-9.

[7] A. L. S. Santos, V. E. Amaro, and M. S. T. Santos, "Terrestrial laser scanner applied to monitoring beach morphological changes in a high energy coastal zone in northeast brazil," in Proc. 7th Int. Terrestrial Laser Scanning User Meet., Rome, Italy, 2014, pp. 1-13.

[8] Dynascan: Mobile Vehicle \& Marine Vessel LiDAR, 1st ed. Houston, TX, USA: Measurement Devices, 2014, pp. 1-6.

[9] Quickstarter v7.5-QINSy User Manual, 2nd ed., Zeist, The Netherlands Quality Positioning Services, 2006, pp. 1-142.

[10] Leica Cyclone SURVEY 8.0: Processing Laser Scans Into Civil/Survey Deliverables, 1st ed., Leica, Heerbrugg, Switzerland, 2011, pp. 1-2.

[11] N. Brodu and D. Lague, "3D Terrestrial LiDAR data classification of complex natural scenes using a multi-scale dimensionality criterion: Applications in geomorphology," ISPRS J. Photogramm. Remote Sens., vol. 68, pp. 121-134, Mar. 2012.

[12] FUSION/LDV: Software for LiDAR Data Analysis and Visualization, 3rd ed., United States Department of Agriculture, Seattle, WA, USA, 2015, pp. $1-186$.

[13] ArcGIS Help 10.2, 10.2.1, and 10.2.2, Environmental Systems Research Institute, New York, NY, USA, 2014.

[14] C. D. Ghilani and P. R. Wolf, "Area" in Elementary Surveying: An Introduction to Geomatics, 13th ed. Upper Saddle River, NJ, USA: PrenticeHall , 2012, pp. 309-330.

[15] A. M. G. Tommaselli, M. V. A. de Moraes, L. S. Silva, M. F. Rubio, G J. Carvalho, and J. T. G. Tommaselli, "Monitoring marginal erosion in hydroelectric reservoirs with terrestrial mobile laser scanner," Int. Arch. Photogramm., Remote Sens. Spatial Inf. Sci., vol. XL-5, pp. 589-596, 2014.

[16] R. B. Langley, "RTK GPS," GPSW, GPS World, vol. 9, no. 9, pp. 70-76, Sep. 1998.

[17] M. F. Rubio, "Gênese e dinâmica de erosões em margens de reservatórios. Pesquisa e desenvolvimento no estudo de caso nas UHEs Chavantes Chavantes e Rosana (rio Paranapanema, SP/PR)," Ph.D. dissertation, Departamento de Geografia, Faculdade de Filosofia, Letras e Ciências Humanas, Universidade de São Paulo, São Paulo, Brazil, 2014.

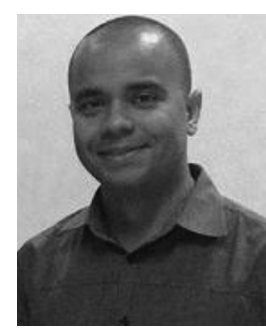

Marcus Vinícius Antunes de Moraes received the B.S. degree in cartography engineering and M.S. degree in geodesic science from the Universidade Estadual Paulista (UNESP), Presidente Prudente, Brazil, in 2013 and 2016, respectively.

He is currently the Technical Research Support at the Photogrammetry Research Group, UNESP.

Mr. de Moraes has been a member of the Photogrammetry Research Group, UNESP, since 2009.

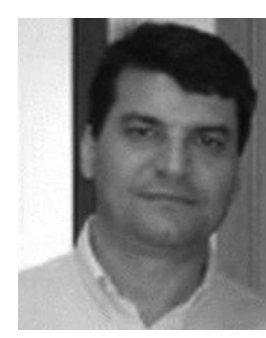

Antonio Maria Garcia Tommaselli received the B.S. degree in cartography engineering from the Universidade Estadual Paulista (UNESP), Presidente Prudente, Brazil, in 1983, the M.S. degree in geodesic science from the Federal University of Paraná, $\mathrm{Cu}$ ritiba, Brazil, in 1988, and the D.S. degree in electrical engineering from the University of Campinas, Campinas, Brazil, in 1993.

From 1988 to 2009, he was an Assistant Professor at the Department of Cartography, UNESP, where he is currently a Full Professor at the Department of

\section{Cartography, UNESP.}

Dr. Tommaselli is member from the International Society for Photogrammetry and Remote Sensing, Cochair of ISPRS Working Group V_I -Land-based Mobile Mapping Systems, and a Leader of Photogrammetry Research Group of the UNESP. 


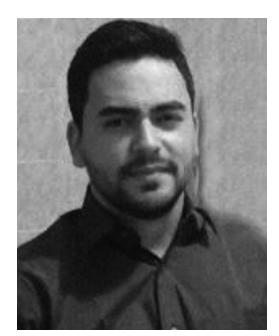

Lucas Dias Santos is currently working toward the B.S. degree in cartography engineering at Universidade Estadual Paulista, Presidente Prudente, São Paulo, Brazil.

In 2014, he was an exchange student at Univesidad Politécnica de Madrid.

Mr. Santos is a member from the Photogrammetry Research Group, Universidade Estadual Paulista.

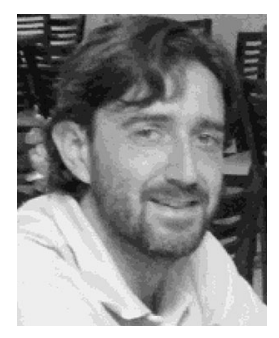

Mauricio Fava Rubio received the B.S. degree in geography and M.S. and D.S. degrees in geography from the University of São Paulo, Presidente Prudente, São Paulo, Brazil, in 2003, 2008, and 2015, respectively.

From 2010 to 2015, he was an Environmental Consulting at Duke Energy-Geração Paranapanema. He is currently an Environmental Consulting at Amabelt Consulting, São Paulo.

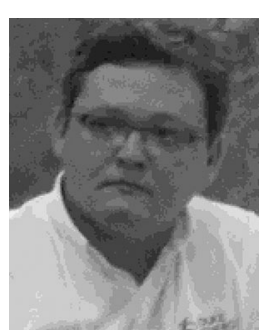

Guilherme Jardim Carvalho received the B.S degree in agronomy from Universidade Estadual Paulista, Ilha Solteira, Brazil, in 2004.

Since 2010, he has been a Patrimony Analyst with Duke Energy-Geração Internacional, São Paulo, Brazil.

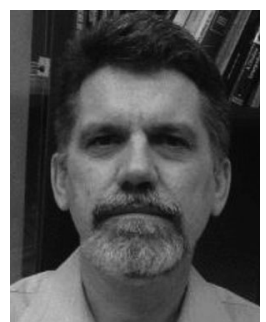

José Tadeu Garcia Tommaselli received the B.S. degree in cartography engineering from the Universidade Estadual Paulista (UNESP), Presidente Prudente, Brazil, in 1982, the M.S. degree in agronomy, and the D.S. degree in science from the University of São Paulo, Piracicaba, Brazil, in 1992, and 1997, respectively.

Since 1987, he has been a Professor at the Department of Geography, Universidade Estadual Paulista (UNESP), and responsible for the disciplines of climatology, meteorology, hydrology, and environmental sciences. 